\title{
Determining Factors for Pertussis Vaccination Policy: A Study in Five EU Countries
}

\author{
Anabelle Wong $1,2,3, *\left(\mathbb{C}\right.$, Annick Opinel ${ }^{1}\left(\mathbb{D}\right.$, Simon Jean-Baptiste Combes ${ }^{4,5}{ }^{\oplus}$, \\ Julie Toubiana ${ }^{6,7,8}$ and Sylvain Brisse ${ }^{6,7}$ (i)
}

1 Institut Pasteur/INSERM/University of Versailles Saint Quentin, UMR 1181 Biostatistics, Biomathematics, Pharmacoepidemiology and Infectious Diseases, 25 rue du Dr Roux, CEDEX 15, F-75724 Paris, France; annick.opinel@pasteur.fr

2 EHESP French School of Public Health, F-35000 Rennes, France

3 ScHARR, The University of Sheffield, 30 Regent Street, Sheffield S1 4DA, UK

4 Univ Rennes, EHESP, CNRS, ARENES-UMR 6051, F-35000 Rennes, France; simon.combes@ehesp.fr

5 French Collaborative Institute on Migration, 93322 Aubervilliers, France

6 Institut Pasteur, Unit Biodiversity and Epidemiology of Bacterial Pathogens, 25 rue du Dr Roux, CEDEX 15, F-75724 Paris, France; julie.toubiana@pasteur.fr (J.T.); sylvain.brisse@pasteur.fr (S.B.)

7 National Reference Center for Whooping Cough and OtherBordetella Infections, Institut Pasteur, 25 rue du Dr Roux, CEDEX 15, F-75724 Paris, France

8 Department of General Paediatrics and Infectious Diseases, Necker-Enfants malades University Hospital, Université de Paris, AP-HP, 135 rue de Sevres, 75015 Paris, France

* Correspondence: anabellewong.hk@gmail.com

Received: 8 December 2019; Accepted: 21 January 2020; Published: 26 January 2020

\begin{abstract}
Pertussis vaccination policy varies across Europe, not only in the type of vaccine-whole cell $(\mathrm{wP})$ vs. acellular $(\mathrm{aP} 1 / 2 / 3 / 5)$ - but also in the schedule and recommendation for parents. This study aims to investigate the determining factors for the type of vaccine, immunization schedule and maternal immunization recommendation. From March to May 2019, experts in national health agencies and major academic or research institutions from Denmark, France, Poland, Sweden and the UK were invited to a semi-structured interview. Thematic analysis was performed on the transcripts using a codebook formulated by three coders. Inter-coder agreement was assessed. Fifteen expert interviews were conducted. The identified driving factors for pertussis vaccine policy were classified into three domains: scientific factors, sociological factors, and pragmatic factors. The determining factors for the type of vaccine were prescriber's preference, concern of adverse events following immunization (AEFI), effectiveness, and consideration of other vaccine components in combined vaccines. The determining factors for infant schedule were immunity response and the potential to improve coverage and timeliness. The determining factors for maternal immunization were infant mortality and public acceptability. To conclude, socio-political and pragmatic factors were, besides scientific factors, important in determining the pertussis vaccine type, schedule of childhood immunization and recommendations for parents.
\end{abstract}

Keywords: Bordetella pertussis; whooping cough; vaccination policy; national immunization program

\section{Introduction}

Whooping cough is an acute respiratory infection characterized by repeated, intense cough bouts that can last for 2 to 3 months [1]. In 1906, the pathogen causing whooping cough was found to be a Gram-negative bacterium, Bordetella pertussis (B. pertussis) [2]. It is highly contagious and spreads via droplets of the coughs or sneezes of an infected person [1]. Before vaccines became available, it was a major cause of infant mortality [3]. 
The earliest vaccines against pertussis were inactivated whole cell pertussis vaccines (wP) developed in 1930s to 1950s; routine pertussis vaccination in children less than 12 months started in the late 1950s in Europe [4]. wP have been replaced by acellular pertussis vaccines (aP) in many European countries since the 1990s [2,5]. aP do not contain the whole bacterium but only antigens; it was suggested that aP have lower reactogenicity and are better accepted [3].

After more than half a century, whooping cough has yet to be eradicated and there are signs for resurgence despite routine childhood immunization [3,6] with high coverage [5]. Some authors have hypothesized that the resurgence is due to short-lived protection from aP compared to wP [6,7]. Nevertheless, the waning of immunity from aP cannot explain all of the resurgence. For example, in the Netherlands and in Denmark, the incidence of whooping cough began to surge before wP were replaced by $\mathrm{aP}$ in the national immunization program [6,8]. Evidence from recent research supports the adaptation of $B$. pertussis to vaccine-induced immunity through antigen evolution $[7,9]$. Most notably, some strains of pertussis no longer produce pertactin (PRN) [3-5,10], a protein that enables the bacteria to attach to the lining of human's airway [11] and which is one of the components used in 3-component (aP3) and 5-component (aP5) vaccines [3-5,10,11]. The PRN-negative characteristic appears to give B. pertussis an advantage in surviving in aP-vaccinated populations [5,11-13]. However, other vaccine components continue to provide protection against $B$. pertussis. Currently, there is no evidence that the PRN-negative strains cause more severe pertussis infection [14,15] and one study showed that the proportion of apnea was lower among PRN-negative cases [12].

Pertussis vaccination is an indispensable strategy towards disease control and prevention. However, the dynamics of vaccination policy are complex. Understanding determinants of vaccine policy is a step forward in the optimization of national immunization efforts. The scope of this study focuses on the relationships of the content and context of pertussis vaccination in Europe. The content is defined as (i) the type of vaccine, (ii) national immunization schedule and (iii) recommendations for pregnant women in pertussis vaccination; while the context comprises determining factors for the policy.

The type and schedule used in the national immunization programs in Europe have evolved since the introduction of pertussis vaccine in 1950s (Supplementary Table S1) [3,4,6,16-50], leading to considerable heterogeneity in pertussis vaccination policies across Europe. Currently, the most common type of vaccine used in Europe is multi-component aP (aP2/3/5). Two-component aP (aP2) contains two antigens: pertussis toxoid (PT) and filamentous haelagglutinin (FHA); aP3 contains the additional antigen PRN; and aP5 contains PT, FHA, PRN, and fimbriae (Fim) types 2 and 3 [4]. While France allows the use of all three types of multicomponent aP, Denmark had until recently relied exclusively on a 1-component aP vaccine (aP1) that contains only PT [51]; whereas Poland remains the only country in Europe that uses wP in the national childhood immunization scheme [46]. Given the existing evidence on efficacy and safety of pertussis vaccines and the similar profiles of $B$. pertussis strains circulating in Europe $[3-5,9,10]$, such diverse vaccination policies across Europe lead to the hypothesis that pertussis immunization strategy is not solely determined by scientific factors but may also be influenced by socio-historical factors as well as pragmatic reasons.

Two main patterns of the first series of pertussis immunization schedules for children are currently used in Europe [16]: (i) the accelerated schedule: 2/3/4 or 2/4/6 month with or without the 4 th dose before the age of 2 years; and (ii) the long schedule: $2 / 4 / 11$ or 3/5/12 month.

The accelerated schedule consists of three doses of vaccines in the first 6 months of life whereas the three doses of vaccines in the long schedule are given over a span of 11 to 12 months [52]. The immunization schedules vary among countries using the same type of vaccine. The initiation of infant immunization can be at 2 or 3 months. Studies conducted in the 1990s did not offer conclusive evidence. Some studies suggested higher serological response using the long schedule $[53,54]$; however, no good serological correlate of protection has been identified [52]. Systematic review also found no good data for the comparison of different schedules in terms of effectiveness [52]. Besides, the evidence of the age of infant immunization initiation having an impact on immunogenicity or effectiveness 
is limited [52]. Under such circumstances, the observation of the variation of infant immunization schedule further supports the hypothesis that pertussis immunization strategy is influenced by factors other than existing evidence in efficacy or effectiveness. This study aimed to investigate the factors that determined the pertussis immunization strategy in European countries that have distinctive vaccination policies.

\section{Materials and Methods}

\subsection{Selection of Countries}

Official reports from national health agencies and scientific and medical journals were reviewed $[3,4,6,16-50]$ to provide information on the current pertussis vaccination policy in $11 \mathrm{EU}$ countries that have participated in any one of the four EuPertStrain studies (Supplementary Table S1). The EuPertStrain studies were established within the European network in 2011, aiming to monitor changes in the European B. pertussis populations in order to optimize vaccine strategies [3-5,10]. Figure 1 shows the type of vaccine used and the first series schedule of childhood immunization in 11 EU countries. Five of these countries were then selected for a qualitative study based on the type of vaccine being used, different recommendations for parents, and different schedules for childhood immunization.

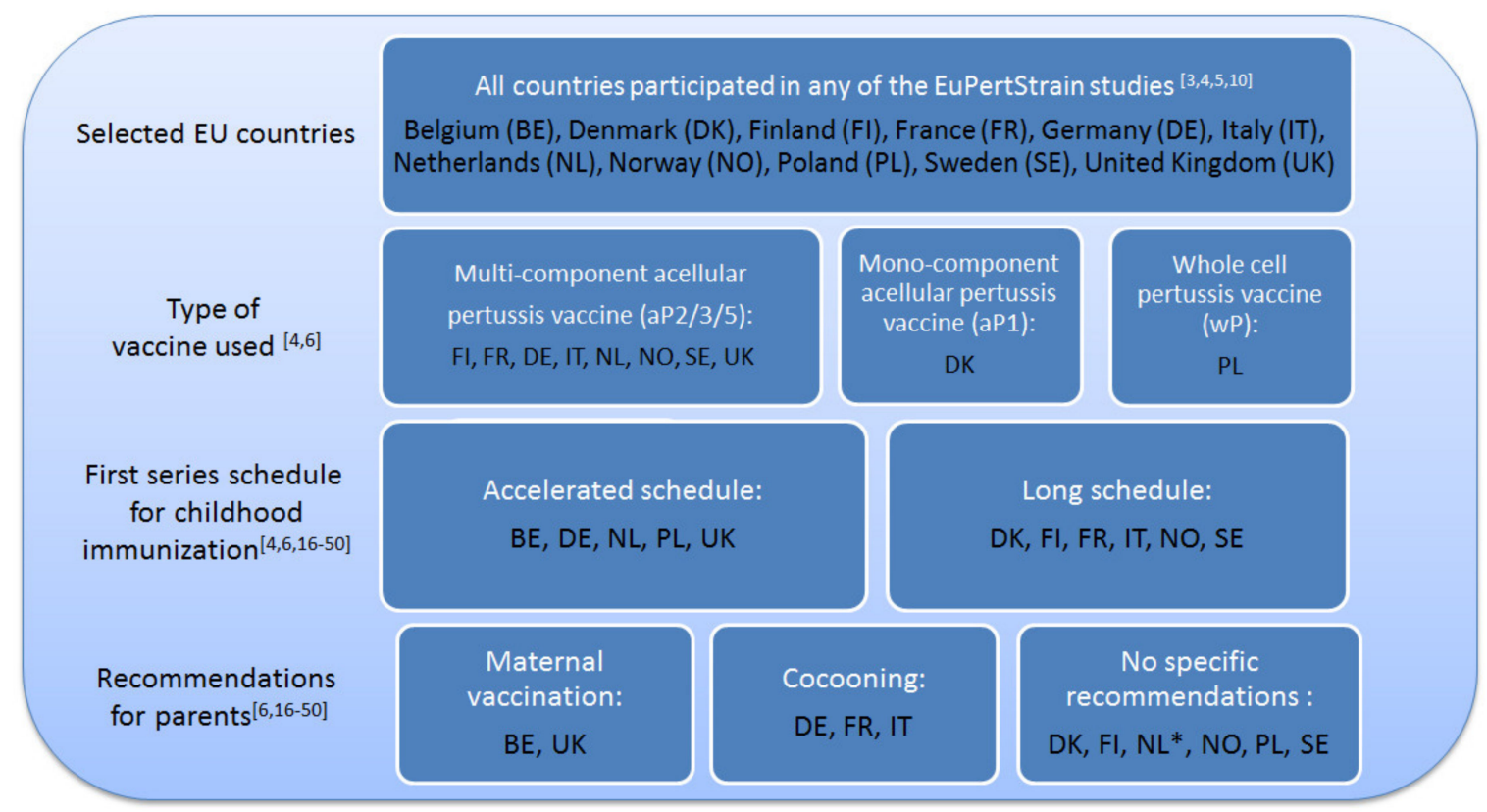

Figure 1. The type of vaccine used, the first series immunization schedule and recommendations for parents in $11 \mathrm{EU}$ countries (* NL started recommendations for maternal vaccination during the study).

Denmark and Poland were selected due to the unique immunization agents used. The UK was selected as it is the first country in Europe to have implemented mass vaccination for pregnant women [1]. France was selected due to its recommendation for the cocooning strategy-a strategy that aims to fill the vulnerable gap for pertussis infection in children between 0 to 6 weeks by vaccinating the individuals in close contact with the newborn $[16,33]$. Owing to a unique history of using aP1 exclusively in Gothenburg from 1996 to 1999 [50] and its "vaccine vacuum" from 1979 to 1996, Sweden was also included in this study to contribute information about vaccine policy evolution. In terms of childhood immunization schedule, Poland and the UK adopted the accelerated schedule while Denmark, France and Sweden followed the long schedule. 


\subsection{Methods for Interviews}

Semi-structured interviews with experts in selected countries were conducted to gain understanding on the factors determining pertussis vaccination policy. Key informants were selected due to their role, experience and knowledge in the field of childhood immunization [55]. The purpose of a semi-structured interview was to encourage expert participants to share their observation and understanding about the phenomenon in vaccination policy making. Experts were identified in the process of literature review and via searching the official websites of major academic and national institutions in selected countries. Individuals who fulfilled the inclusion criteria (Table 1) were recruited. Further informants were recruited by snowball sampling because sampling in this study was purposive and it aimed at maximum variation of information [56]. The sampling frame aimed to recruit experts from different professional backgrounds within the same country and to obtain representation from experts involved in policy decisions as well as those who were not involved in the national decision process. Interviews were conducted in person or via Skype or phone when a face-to-face meeting could not be arranged. The interviews followed a set of open-ended questions in the topic guide (Supplementary File S2) developed based on Boyce and Neale's template [57]. The interviews were audio-recorded and transcripts were produced based on the audio-file. The transcripts were sent back to participants for checking and signing as an endorsement of accuracy. Upon receiving the endorsed transcript, the audio-recording would be deleted. In cases where the expert had not sent back an endorsed transcript, draft transcript was used for analysis while pending future transcript endorsement to trigger the deletion of the audio-file. The transcripts were anonymized by the allocation of a transcript ID.

Table 1. Inclusion and exclusion criteria for participant recruitment.

\section{Inclusion Criteria}

(1) Have work experience of 3 years or above in the field related to vaccination policy or pertussis research in the country;

(2) Have professional knowledge on pertussis vaccine or vaccination policy in the country;

(3) Are able to communicate effectively in English;

(4) Are willing to participate and have given informed consent.

\section{Exclusion Criteria}

(1) Vaccine manufacturers and their employees;

(2) Withdrawn consent during or after interview.

Demographic information and characteristics of participants were summarized by descriptive statistics. Thematic content analysis was performed on the anonymized transcripts using a codebook formulated based on grounded theory. It means that the codebook did not rely on any pre-existing theory but consisted of recurrent concepts emerged from the interviews; therefore the codebook was considered grounded in data [58]. The process of coding was guided by the 3-stage approach proposed by Campbell and colleagues [59]. In the first stage, a codebook (Supplementary File S3) by one knowledgeable coder was developed based on all transcripts. A knowledgeable coder was defined as a coder who had insights on all transcripts. This codebook was used by three independent analysts to code two pilot transcripts: one from the interview with a health scientist and the other with a social scientist. As the vocabulary used and the concepts brought up by experts with these professional backgrounds can vary significantly, the code used would vary accordingly. The second stage involved adjudicating coding disagreement through discussion [59]. In this stage, the codebook was refined as ambiguous and overlapping codes were deleted and necessary new codes created based on the consensus of the three coders. Inter-coder agreement was assessed after pilot coding. In the third stage, the codebook was deployed to the full set of anonymized transcripts by one knowledgeable coder once inter-coder agreement was established. All codes were arranged into categories and plotted for conceptualization. All transcripts were processed in R version 3.5.1 and RStudio version 1.1.456 using the package "RQDA". 
Inter-coder agreement was assessed using Krippendorff's alpha, which is a generalized version of inter-rater agreeability statistic that can be applicable in nominal data and in situations where there are more than 2 observers [60]. The interpretation of Krippendorff's alpha was based on the guideline drawn up by Landis and Koch [61].

\subsection{Ethical Approval}

The study has obtained approval from the Ethical Committee (EC) of the University of Sheffield, UK. Regarding the nature and study design of this study, EC approval or notification was not required in Denmark, France, Poland and Sweden. Further to EC requirements in selected countries, this study observed and complied with the EU General Data Protection Regulation (GDPR) as well as the country-specific regulations if the scope of such regulation applied.

\section{Results}

From March to May 2019, 34 experts were contacted, and 15 interviews had been conducted by the end of May, 2019. The 15 experts had experience ranging from 5 to 35 years and the median year of experience was 18 years. Table 2 shows more demographic information including country, professional background and whether the expert was involved in the vaccination policy process.

Among the 19 non-responders, 6 declined for not having sufficient knowledge or experience in the topic, not being actively involved in related duties anymore, or being too occupied with other priorities. The characteristics of the non-responders were analyzed. Non-responders more often came from Sweden and the UK $(n=15)$; and were more often experts in the field of social and political science $(n=10)$.

Table 2. Demographic characteristics of participants.

\begin{tabular}{ccc}
\hline Demographic Characteristics & Information from Participants a & $\boldsymbol{n}$ \\
\hline Total & & 15 \\
\hline \multirow{3}{*}{ Country } & Denmark & 3 \\
& France & 4 \\
& Poland & 2 \\
& Sweden & 3 \\
Professional background & UK & 3 \\
& Social \& Political Science & 4 \\
& Epidemiology \& Medicine & 7 \\
& Microbiology \& Immunology & 4 \\
\hline \multirow{2}{*}{ Involvement in Policy Process } & Yes & 9 \\
& No & 6 \\
\hline \multirow{2}{*}{} & \multicolumn{2}{c}{}
\end{tabular}

\subsection{Inter-Coder Agreement}

The longest transcript from experts with a health science background and that from experts with a social science background were selected for assessing inter-coder agreement. Inter-coder agreement from the two transcripts among the three coders was assessed using Krippendorff's alpha (Table 3). Disagreements can come from the inconsistency within one coder [60], which was minimized by instructing all coders to read the whole transcript before starting to code. Disagreements can also come from the inter-coder differences in the interpretation and application of the coding guidelines [60].

The Krippendorff's alpha based on the health scientist's transcript was slightly higher than that based on the social scientist's transcript. The small difference between the Krippendorff's alphas of the three coders based on the two transcripts also suggested that the levels of agreement among coders were similar when interpreting discussions offered by experts of different backgrounds. The overall inter-coder agreement by Krippendorff's alpha was 0.616 , indicating substantial agreement according to Landis and Kock's interpretation framework (Table 2) [61]. 
Table 3. Inter-coder agreement in pilot coding using two transcripts.

\begin{tabular}{cccc}
\hline Interviewee Category & Coding Unit & Krippendorff's Alpha [60] & Interpretation [61] \\
\hline Epidemiology \& Medicine & 75 & 0.621 & Substantial Agreement \\
Social \& Political Science & 57 & 0.598 & Moderate Agreement \\
\hline Total & 132 & 0.616 & Substantial Agreement \\
\hline
\end{tabular}

\subsection{Determining Factors of Pertussis Vaccination Policy}

The determining factors referred to the reasons for the change in policy or the ground for policies remaining unchanged. These factors were identified from the interviews and triangulated by experts from the same country.

The codes derived from the transcripts were categorized into three domains: scientific factors, sociological factors, and pragmatic factors. Figure 2 shows the determining factors for pertussis vaccination policy under different domains.

a

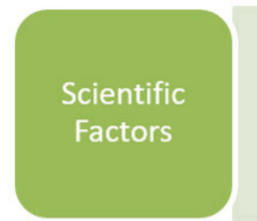

- Cases /epidemics / outbreaks

- AEFI / safety profile

- Surveillance / data availability

- Immunity response

- Duration of protection

- Public acceptance \& uptake

- Social contact structure

- Attitude \& behaviour of HCP

- Attitude \& behaviour of public
- Infant death \& non-fatal outcomes

- Transmission in population

- Effectiveness

- Protect mothers/infants \& herd immunity

- Technical production process b
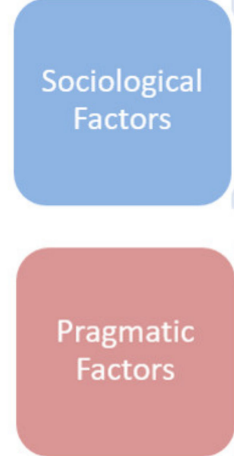

- Marketing authorisation

- Cost-effectiveness

- Affordability \& cost / price
- Awareness \& perception of pertussis

- Historical events / vaccine scares

- Trust in HCP \& authorities

AEFI = Adverse Events Following Immunization; HCP = Health Care Professionals

Figure 2. Determining factors of pertussis vaccination policy: (a) scientific factors; (b) sociological factors; (c) pragmatic factors.

\subsubsection{Type of Vaccine}

Regarding the change from $\mathrm{wP}$ to $\mathrm{aP}$, a range of reasons were mentioned. While most experts $(n=10)$ believed the concern of adverse events following immunization (AEFI) was causing the change, some experts who were involved in the decision making process pointed out other more proximal reasons $(n=5)$ for the change in the type of vaccine being used in the national immunization program.

Experts in France stated that the prescriber's preference contributed to the change. According to the experts, the country recommended using $\mathrm{wP}$ in the first series of childhood immunization until 2004; however, since the introduction of aP booster for the age group of 11 to 14 years in 1998 in France and subsequent availability of aP, many general practitioners and pediatricians prescribed aP for the prime vaccination of the infants. According to the experts, due to increasing consumption of aP and decreasing demand of $\mathrm{wP}$, manufacturers decided to produce only aP instead of maintaining two production lines. That ultimately caused the change in recommendation from using $\mathrm{wP}$ to $\mathrm{aP}$ in the immunization for all age groups.

Experts in Sweden pointed out the fact that despite a high coverage of wP before the change, pertussis cases in infants were not reduced. Therefore, the wP vaccine was deemed ineffective and the national pertussis immunization program was suspended from 1979 to 1996. It was resumed when aP became available and after its effectiveness had been proven. 
In the UK, wP was recommended for the infant immunization program until 2004. According to the experts, coverage of the vaccine program plummeted due to concern about AEFI in the 1970s and 1980s, but confidence was restored in wP given abundant efforts in independent review about the safety of the $\mathrm{wP}$ vaccine, leading to increased and sustained high coverage. The change from $\mathrm{wP}$ to aP was actually driven by the need of an inactivated polio vaccine, which was available in a multivalent vaccine that contained an aP component.

Poland was the only country in the EU that is still using wP. According to the experts in Poland, the ${ }_{\mathrm{WP}}$ used had desirable effectiveness and did not induce concern about AEFI. As the vaccine was produced in the country, the supply was stable. It was also a more affordable option.

Regarding the switch from $\mathrm{aP} 1$ to $\mathrm{aP} 2 / 3 / 5$, experts from Sweden shared that it was the tender process that drove the change. As aP1 vaccines were only produced in Denmark, since the manufacturer did not participate in the tender process, it was not available for selection in the Swedish national immunizations program. Before this study commenced, Denmark was the only country that had been using aP1 [51] since the change from wP to aP in 1997. However, experts in Denmark reported in the interview during this study that the country has just changed from using aP1 to aP2/3/5 and the reason was also due to aP1 manufacturer stopping its participation in the tender process.

\subsubsection{Immunization Schedule}

Concerning the accelerated and long schedule for infant immunization, most experts regarded it to be a decision based on clinical data from trials of the vaccines and the authorized posology recommended by manufacturers. However, since both schedules were proven to be effective and the recommendation by the World Health Organization (WHO) also allows certain flexibility [62], countries made their decisions based on various factors and priorities.

Experts from Denmark and Sweden, where long schedule (3/5/12 month) was used, shared that such decision was based on data from clinical trials within the country and that such schedule allowed desirable immunogenicity and effectiveness.

"That was in the 80s, we looked at the pertussis trial and we found that the immune response is the best if you give the vaccine at 2-month intervals instead of 1-month intervals. And it's better to start at the age of 3 month compared to 2 month ..."

(Sweden expert)

France adopted the accelerated schedule in 1995 but has changed to a long schedule in 2013. However, in 2013, France used a long schedule that consisted of three doses at 2, 4, 11 month instead of the 3/5/12 month standard long schedule. According to the experts, an earlier initiation of immunization was due to the concern of cases in very young infants - those who might be infected by pertussis before receiving the first dose of vaccine at the age of 3 month according to the standard long schedule.

"And in France, we decided to adopt such a schedule but we did not want to start at 3 month because we knew that if you start one month later, you will have more pertussis cases. So we chose to start at 2 months..."

(France expert)

The accelerated schedule (2/3/4 month) was used in the UK. Experts shared that when the 3rd dose of primary pertussis vaccination was closer to an older infant age around 11 month, there was a drop-off in uptake of that 3rd dose. By adopting the accelerated schedule, coverage was increased and timeliness of the three doses of first series of vaccine was improved.

"The advantage of having an accelerated course is that you're not only offering protection at an earliest infant age but also we've found that you're more likely to achieve higher uptake, when you're offering it at an earlier age."

(UK expert) 


\subsubsection{Maternal Vaccination}

A consensus was observed among experts from different countries that the main reason for recommending vaccination during pregnancy was an epidemic or increased infant death.

" ... we have no, well, very few infant deaths. And that is the major marker for introducing the vaccination in pregnancy, of course. We had an epidemic in 2016. And that's prompted, the Health Authority to think about renewing the vaccination strategies. And vaccination in pregnancy was one of them although we haven't implemented it."

(Denmark expert)

"So now it has changed in favor of maternal vaccination. Pertussis is not a big problem for the moment, but in case there will be an increase of infants infectedwith pertussis, I think there will be a change in the program towards this recommendation."

(Sweden expert)

"We experienced a very significant increase in overall rate of disease across the entire population, but particularly in those very young babies. And we had an increase in pertussis deaths, we had 14 deaths from pertussis in 2012. So the introduction of the maternal program was very much introduced and prompted by the increased rate of disease. We've done it as an emergency program ..."

(UK expert)

In countries where infant deaths remained low, such as Denmark and Sweden, experts suggested that maternal vaccination would enter the policy discussion when pertussis-related infant deaths increased. In the UK, where a major epidemic with increased infant deaths occurred in 2012, such strategy was adopted as a response to the emergency.

However, there were also recurrent concerns about such policy. These concerns included acceptability of maternal immunization by health care professionals (HCP) and by the general public and the limited data on immunity blunting, which is a phenomenon where trans-placentally acquired antibody lowers the immune response to infant immunization [19].

"Well, it's typical that one reason why we didn't jump at that strategy is that we have the question mark of what will be the acceptance rate of such a strategy."

(France expert)

"... we have an investigation in the public health agency a couple of years ago. At that time, there was some hesitancy. They were looking for more data. There's some kind of blunting or immune response in the children."

(Sweden expert)

\subsubsection{Other Important Discourse: Policy Implementation}

During the interviews, some experts $(n=2)$ expressed that pertussis vaccination was not a frequently debated topic in the country as vaccination debates focused on other vaccines, such as HPV vaccines.

Some experts $(n=3)$ offered a discussion on the paradigm of vaccination policy process. In Poland, there was recently a vote in parliament about abolishing mandatory vaccination, which was triggered by citizens' petition; and in France, there had been a citizen consultation before the country expanded mandatory vaccination in 2018 from 3 vaccines to 11 vaccines. Those events led countries to discuss themes related to public-professional and public-authority relationship. Some experts shared that they were concerned about how policy was made would have an impact on the perception, attitude or behavior of the general public regarding vaccination or towards HCP: 
"And something that might fuel distrust towards the expert professionals, in Poland at least, is the strength and unquestionability of the consensus already existing among professionals."

(Poland expert)

The use of mandatory vaccination may lead some people to be more radical:

" ... that doesn't mean they were against vaccines, it just means that they were against mandatory vaccination ... is it going to push part of the people who are hesitant towards a more radical stance, you know, going to very private schools, where they look the other way and don't really check whether the children are vaccinated? And the issue is whether it's going to create small pockets of severely under-vaccinated people..."

(France expert)

According to the some experts, mandatory vaccination may be seen as a way to restore public confidence in vaccines in France and as the consensus or approval of the authority and professionals in Poland. Other countries found voluntary vaccination based on national recommendation a better suiting strategy. Some experts also expressed doubts about the message or implication conveyed by vaccine mandates:

"I can't see a reason for introducing a compulsory element to this because it's a program that's already very well delivered and very well received. So I can't see a role for mandating in our population at this time. And I doubt it would improve uptake, and it could be counterproductive."

(UK expert)

" ... but if the results speak for themselves and the health authorities recommend something, people tend to do that. And I believe, and I know I'm not alone in believing that, if we were to make mandatory vaccination, it would actually spark this hesitancy, it would spark distrust. And I think it would be detrimental for our program to do that."

(Denmark expert)

\section{Discussion}

In this work we first reviewed the literature to define the extent of variation of vaccination policies across EU countries. We then selected 5 countries with contrasted policies to conduct an investigation of vaccination policy determinants. In the semi-structured interview, experts from Denmark, France, Poland, Sweden and the UK were asked about their perception of the determinants for changes in the type of pertussis vaccine $(\mathrm{wP} / \mathrm{aP} 1 / \mathrm{aP} 2,3,5)$ and schedule being used in the national childhood immunization program, and the reasons for such changes, if any. Experts were also asked why cocooning strategy or maternal vaccination might be important to the country, if there was such recommendation in place.

All participating countries except Poland experienced the switch of $\mathrm{wP}$ to aP in national immunization against pertussis. Although it is widely believed that aP is better tolerated than $\mathrm{wP}$ [3], it was not the main reason for the switch in France, Sweden and the UK. Moreover, the wP in Poland did not trigger concern about AEFI. An explanation for these observations is that wP, of which the production process is not standardized, showed different efficacies and safety profiles in different countries, leading to heterogeneity in the discontinuation or continuation of $\mathrm{wP}$ in national immunizations program.

One of the recurrent messages brought up by experts was the inappropriate comparison between $\mathrm{wP}$ and $\mathrm{aP}$ in literature and in nowadays' debates. Experts reminded researchers and policy makers that $\mathrm{wP}$ and aP comparison would not be meaningful and can be misleading when the strain of $\mathrm{wP}$ was not specified or characterized. The efficacy and safety profile of wP depended on the specific strain 
and the production of the vaccine. Some countries used locally produced wP; therefore the quality, efficacy and safety profile of the vaccines across countries would vary. Even within the same country, $\mathrm{wP}$ still varied from year to year, and from batch to batch. This also explained why the decision of using $\mathrm{wP}$ or aP and the reasons for the switch differed from country to country. If the country had a $\mathrm{wP}$ with good effectiveness and desirable safety profile, $\mathrm{wP}$ tended to remain in use for longer periods. As different $\mathrm{wP}$ have different safety profiles, it is therefore important to be precise about the $\mathrm{wP}$ when the concern of AEFI is addressed.

Often mentioned was the "side effects" or "safety profile" of wP but the more important concept is the distinction between the actual AEFI that occurred and the concern about the AEFI. The former is a factual concept-frequency and severity of the AEFI that occurred; the latter is a concept about perceived risk and a measure of attitude.

Looking closer at the driving factors for the change from $\mathrm{wP}$ to aP in the selected countries, there appeared to be an interdependent relationships among scientific factors, sociological factors and pragmatic factors. This study leads us to propose a mechanism of influences among cases of AEFI, the concern about AEFI and the behavioral adaptation (Figure 3). Hidden influence or relationship, such as the influence from manufacturer on HCP and policy makers, or the influence from media and social media on HCP and policy makers, can be present. The existing literature on vaccination policy also highlighted that transparency of the decision process needs improving [63]. Therefore, while deciphering the driving factors in vaccination policy, one must bear in mind the potential hidden driving factors or the concealed relationship between factors.

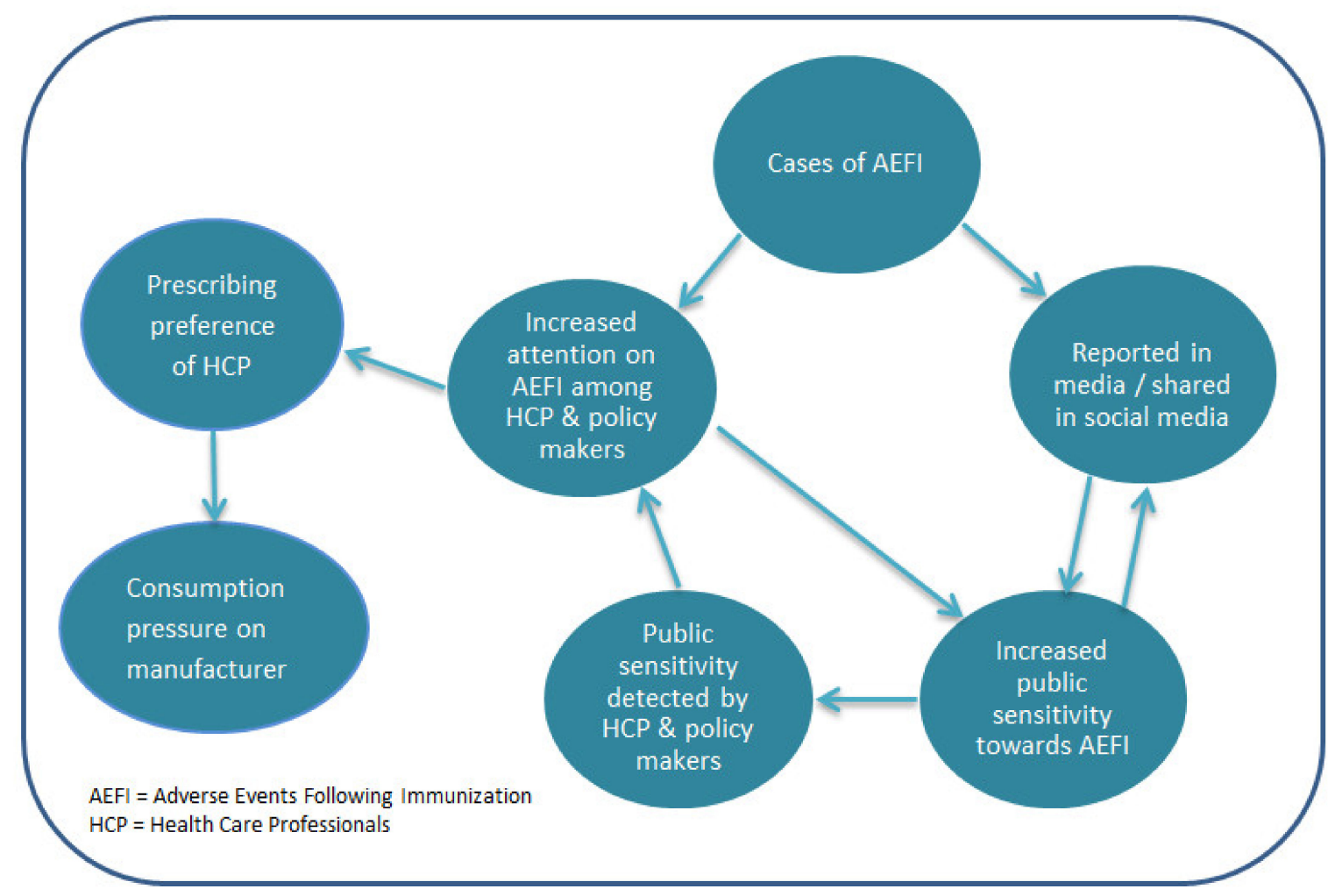

Figure 3. Relationship between adverse events following immunization (AEFI) and the concern about AEFI among public and health care professionals (HCP).

The determination of the childhood immunization schedule against pertussis appeared to result from a balance of three essential factors: (i) immunogenicity; (ii) earliest immunization possible; and (iii) highest uptake possible. These three independent but important factors justify the flexibility 
included in the WHO recommendations [62] and offer a basis for vaccine policy makers to weigh the above-mentioned factors according to the country-specific context.

Closely related to the determination of the childhood immunization schedule are the recommendations for parents. Most experts agreed that maternal vaccination became a topic of discussion when an epidemic or an increase in pertussis-related infant deaths was observed in the country. Such finding is coherent with the policy evolution in the UK, as the UK government introduced a temporary immunization program for pregnant women from October 2012 as a response to the national outbreak declared in April 2012 [64]. Later in June 2014, the Joint Committee on Vaccination and Immunisation (JCVI) advised the program to continue for another five years before further evaluation [64]. Such evaluation shall offer an abundance of evidence that may answer many questions about the longer term safety, efficacy and cost-effectiveness of the national maternal immunization program.

A similar case was observed in an overseas Department of France: the increase in pertussis cases among infants in Mayotte in 2017 has sparked the discussion that led to the implementation of local maternal immunization as a response to the epidemic [65]. The outbreak in Mayotte was partly due to insufficient coverage of childhood immunization program caused by the breakdown of health care infrastructure [65]. Further, the Technical Commission of Vaccinations (Commission Technique des Vaccinations, Haute Autorité de Santé) has affirmed that maternal vaccination is more efficient and beneficial than the cocooning strategy in protecting infants too young to be vaccinated in the context of major epidemics [66]. Hence, the situation in Mayotte might influence an evolution of maternal vaccination recommendations even in mainland France.

Currently, the scientific data about the critical factors related to pertussis vaccine strategy is scarce. As primary research, this study offered abundant data and will allow further analyses. Its sampling frame aimed to obtain representation from all five selected countries. In each country, at least two different professional backgrounds were included in order to maximize data variation and to serve the purpose of triangulation. The median duration of experts' experience was 18 years, indicating that the study sample has long duration of exposure in the field of interest and can be considered as a credible source of information. The data collection relied on audio-recording, together with the transcript endorsement process, which ensured the accuracy of data and thus increased the internal validity of the study. Qualitative research is often attacked for being subjective and biased [67], especially when there is ambiguity in the data or when certain codes belong to more than one coding categories [68]. To increase rigorousness and external validity, this study endeavored to establish a reliable codebook with an assessment of the inter-coder agreement of three coders who had worked on the same set of transcripts $[59,60]$. Although the sample size was small $(n=15)$, no new code arose towards the last few interviews and a large amount of recurrent codes were observed, suggesting saturation of knowledge, which was the purpose of this qualitative research using the method of interview [69].

There were a few limitations in this study. Firstly, the fact that more experts from the field of natural science and health science responded to the study invitation than experts from the field of social and political science might induce bias. Secondly, the set duration of $30 \mathrm{~min}$ was a limiting time frame for an interview, so some participants did not cover all topics on the interview topic guide. Thirdly, as discussed above, hidden external influence such as that from the pharmaceutical industry cannot be assessed. This may or may not have affected the neutrality of experts' opinions [70]. Since participants did not declare conflict of interests, it was not possible to estimate the impact of such influence on this study. As with many studies using the method of qualitative interview, unitization of transcripts was a limitation in this study $[59,60]$. In the content analysis, coding units were "units of meaning" instead of demarcated parts of text. Such unitization, despite being more appropriate in this exploratory research study using complex interview data [59], tends to result in lower inter-coder agreement $[59,60]$. Another limitation of this study is that the codebook was generated by one coder. Lastly, the five countries had different surveillance systems and strategies in place, which may influence the experts' perception of determining factors for pertussis vaccination policy. 


\section{Conclusions}

By disputing the oversimplified version of safety- and efficacy-driven vaccine policy, the findings of this study contribute to a better understanding of the determining factors that drive pertussis vaccination policy. The choice of the immunization agent was influenced by prescriber's preference, concern of adverse events following immunization (AEFI), effectiveness, and consideration of other vaccine components in combined vaccines. The schedule of childhood immunization was determined by immunity response and the potential to improve coverage and timeliness. The recommendations on maternal immunization hinges on infant mortality contributed by pertussis in the country as well as acceptability of such strategy by HCP and the general public.

To better guide pertussis vaccination policy, future researchers should pay attention to the impact of changes in vaccine policies on pertussis epidemiology within a country and dynamics of transmission in Europe and worldwide. More efforts and attention should be given to sociological research on pertussis vaccination strategies, especially on the attitude and behavior of HCP and the public. Including sociological expertise in the decision making and increasing the transparency of decision process may also help build public's trust in the vaccine policy decision process.

Supplementary Materials: The following are available online at http://www.mdpi.com/2076-393X/8/1/46/s1, Table S1: Pertussis Vaccination Policy in 14 EU Countries since Introduction, File S2: Semi-Structured Interview Topic Guide, File S3: Coding Guideline.

Author Contributions: Conceptualization, A.W., A.O., J.T. and S.B.; methodology, A.W. and A.O.; software, A.W. and S.J.-B.C.; validation, A.W., A.O. and S.J.-B.C.; formal analysis, A.W.; investigation, A.W.; resources, A.O., J.T. and S.B.; data curation, A.W.; writing-original draft preparation, A.W.; writing-review and editing, A.O., S.J.-B.C., J.T. and S.B.; visualization, A.W.; supervision, A.O. and S.J.-B.C.; project administration, A.W. and A.O.; funding acquisition, S.B. All authors have read and agreed to the published version of the manuscript.

Funding: This project was funded by the INCEPTION interdisciplinary project at Institut Pasteur, "Understanding whooping cough resurgence in Europe by combing genomic, epidemiological and sociological approaches" (French Government Investissements d'Avenir grant ANR-16-CONV-0005).

Acknowledgments: The research team would like to thank Yoriko Masunaga, Institute of Tropical Medicinein Antwerp; Richard Cooper, University of Sheffield; Didier Guillemot, Tamara Giles-Vernick and Matthieu Domenech de Cellès, Institut Pasteur, for their valuable advice and resourcefulness. We would also like to express our heart-felt gratitude to Daniel Levy-Bruhl, Daniel Floret, Nicole Guiso, Tine Dalby, Michał Zabdyr-Jamróz, Sven-Arne Silfverdal and other experts who have offered their support to this project.

Conflicts of Interest: The authors declare no conflict of interest.

\section{References}

1. National Health Service. Whooping Cough. Available online: https://www.nhs.uk/conditions/whoopingcough/ (accessed on 12 February 2019).

2. Amirthalingam, G.; Gupta, S.; Campbell, H. Pertussis immunisation and control in England and Wales, 1957 to 2012: A historical review. Euro Surveill. 2013, 18, 20587. [CrossRef] [PubMed]

3. Caro, V.; Njamkepo, E.; Van Amersfoorth, S.C.M.; Mooi, F.R.; Advani, A.; Hallander, H.O.; He, Q.; Mertsola, J.; Riffelmann, M.; Vahrenholz, C.; et al. Pulsed-field gel electrophoresis analysis of Bordetella pertussis populations in various European countries with different vaccine policies. Microbes Infect. 2005, 7, 976-982. [CrossRef] [PubMed]

4. Advani, A.; Hallander, H.O.; Dalby, T.; Krogfelt, K.A.; Guiso, N.; Njamkepo, E.; von Könnig, C.H.; Riffelmann, M.; Mooi, F.R.; Sandven, P.; et al. Pulsed-field gel electrophoresis analysis of Bordetella pertussis isolates circulating in Europe from 1998 to 2009. J. Clin. Microbiol. 2013, 51, 422-428. [CrossRef] [PubMed]

5. Barkoff, A.; Mertsola, J.; Pierard, D.; Dalby, T.; Hoegh, S.V.; Guillot, S.; Stefanelli, P.; van Gent, M.; Berbers, G.; Vestrheim, D.F.; et al. Surveillance of circulating Bordetella pertussis strains in Europe during 1998 to 2015. J. Clin. Microbiol. 2018, 56, e01998-e17. [CrossRef]

6. World Health Organization. SAGE Pertussis Working Group Background Paper; World Health Organization: Geneva, Switzerland, 2014.

7. Preston, A. The role of B. pertussis vaccine antigen gene variants in pertussis resurgence and possible consequences for vaccine development. Hum. Vaccines Immunother. 2016, 12, 1274-1276. [CrossRef] 
8. Domenech de Celles, M.; Magpantay, F.M.G.; King, A.A.; Rohani, P. The pertussis enigma: Reconciling epidemiology, immunology and evolution. Proc. R. Soc. B 2016, 283, 20152309. [CrossRef]

9. Bart, M.J.; Harris, S.R.; Advani, A.; Arakawa, Y.; Bottero, D.; Bouchez, V.; Cassiday, P.K.; Chiang, C.S.; Dalby, T.; Fry, N.K.; et al. Global population structure and evolution of Bordetella pertussis and their relationship with vaccination. mBio 2014, 5, e01074-e14. [CrossRef]

10. Hallander, H.; Advani, A.; Riffelmann, M.; von König, C.H.W.; Caro, V.; Guiso, N.; Mooi, F.R.; Gzyl, A.; Kaltoft, M.S.; Fry, N.K.; et al. Bordetella pertussis strains circulating in Europe in 1994 to 2004 as determined by pulsed-field gel electrophoresis. J. Clin. Microbiol. 2007, 45, 3257-3262. [CrossRef]

11. Bouchez, V.; Hegerle, N.; Strati, F.; Njamkepo, E.; Guiso, N. New data on vaccine antigen deficient Bordetella pertussis isolates. Vaccines 2015, 3, 751-770. [CrossRef]

12. Martin, S.W.; Pawloski, L.; Williams, M.; Weening, K.; DeBolt, C.; Qin, X.; Reynolds, L.; Kenyon, C.; Giambrone, G.; Kudish, K.; et al. Pertactin-Negative Bordetella pertussis Strains: Evidence for a possible selective advantage. Clin. Infect. Dis. 2015, 60, 223-227. [CrossRef]

13. Mooi, F.R.; Van der Maas, N.A.T.; De Melker, H.E. Pertussis resurgence: Waning immunity and pathogen adaptation-Two sides of the same coin. Epidemiol. Infect. 2014, 142, 685-694. [CrossRef] [PubMed]

14. Bodilis, H.; Guiso, N. Virulence of pertactin-negative Bordetella pertussis isolates from infants, France. Emerg. Infect. Dis. 2013, 19, 471-474. [CrossRef] [PubMed]

15. Clarke, M.; McIntyre, P.B.; Blyth, C.C.; Wood, N.; Octavia, S.; Sintchenko, V.; Giles, L.; Quinn, H.; Hill, V.; Hanly, G.; et al. The relationship between Bordetella pertussis genotype and clinical severity in Australian children with pertussis. J. Infect. 2016, 72, 171-178. [CrossRef] [PubMed]

16. European Centre for Disease Prevention and Control. Vaccine Schedules in All Countries of the European Union. Available online: https://vaccine-schedule.ecdc.europa.eu/ (accessed on 14 February 2019).

17. Therre, H.; Baron, S. Pertussis immunization in Europe-The situation in late 1999. Euro Surveill. 2000, 5, 6-10. [CrossRef]

18. Van Kerschaver, E. The Belgian expanded Programme on immunization (EPI) and hepatitis B vaccination. S. Afr. J. Epidemiol. Infect. 2008, 23, 40-44. [CrossRef]

19. Maertens, K.; Cabore, R.N.; Huygen, K.; Hens, N.; Van Damme, P.; Leuridan, E. Pertussis vaccination during pregnancy in Belgium: Results of a prospective controlled cohort study. Vaccine 2016, 34, 142-150. [CrossRef]

20. Maertens, K.; Braeckman, T.; Top, G.; Van Damme, P.; Leuridan, E. Maternal pertussis and influenza immunization coverage and attitude of health care workers towards these recommendations in Flanders, Belgium. Vaccine 2016, 34, 5785-5791. [CrossRef]

21. Vaccination Info. [Diseases and Vaccines: Whooping Cough]. Available online: https://www.vaccinationinfo.be/maladie/coqueluche/ (accessed on 19 February 2019). (In French)

22. The Citizens Information Portal of the German-Speaking Community of Belgium. [The Optimal Vaccination Schedule]. Available online: https://translate.google.fr/?hl=en\&tab=rT\&authuser=0\#view=home\&op= translate\&sl=de\&tl=en\&text=Das\%20optimale\%20Impfschema (accessed on 19 February 2019). (In German)

23. Flanders Care and Health. [Basic Vaccination Schedule]. Available online: https://www.zorg-en-gezondheid. be/basisvaccinatieschema (accessed on 19 February 2019). (In Dutch)

24. Heininger, U.; André, P.; Chlibek, R.; Kristufkova, Z.; Kutsar, K.; Manarov, A.; Mészner, Z.; Nitsch-Osuch, A.; Petrović, V.; Prymula, R.; et al. Comparative epidemiologic characteristics of pertussis in 10 Central and Eastern European countries, 2000-2013. PLoS ONE 2016, 11, e0155949. [CrossRef]

25. Chlibek, R.; Smetana, J.; Sosovickova, R.; Fabianova, K.; Zavadilova, J.; Dite, P.; Naplava, P.; Lzicarova, D. Seroepidemiology of whooping cough in the Czech Republic: Estimates of incidence of infection in adults. Public Health 2017, 150, 77-83. [CrossRef]

26. National Immunisation Committee of Czech Republic. Recommendation for Pertussis Vaccination in Pregnancy for the Czech Republic. 2015. Available online: http://www.szu.cz/uploads/Epidemiologie/ Pertuse/CR_Pertussis_Recommendation_for_pregnant_women.pdf (accessed on 14 February 2019).

27. Dalby, T.; Andersen, P.A.; Hoffmann, S. Epidemiology of pertussis in Denmark, 1995 to 2013. Euro Surveill. 2016, 21, 30334. [CrossRef]

28. Zoeldi, V.; Sane, J.; Nohynek, H.; Virkki, M.; Hannila-Handelberg, T.; Mertsola, J. Decreased incidence of pertussis in young adults after the introduction of booster vaccine in military conscripts: Epidemiological analyzes of pertussis in Finland, 1995-2015. Vaccine 2017, 35, 5249-5255. [CrossRef] [PubMed] 
29. Guiso, N. The reality of pertussis vaccination. In Proceedings of the 14th National Day of Infectious Diseases, Clermont-Ferrand, France, 12-14 June 2013. (In French)

30. Technical Committee of Vaccinations (Comité Technique des Vaccinations). The Vaccination against Whooping Cough. In The Vaccination Guide, 2nd ed.; French Committee of Education for Health (CFES): Paris, France, 1999; pp. 67-72. (In French)

31. Technical Committee of Vaccinations (Comité Technique des Vaccinations). The Vaccination Guide; National Institute of Prevention and Health Education (INPES): Paris, France, 2012. (In French)

32. High Council of Public Health (HCSP). Vaccine Schedule and Vaccination Recommendations; National Institute of Prevention and Health Education (INPES): Paris, France, 2015. (In French)

33. National Institute of Prevention and Health Education (INPES). The Vaccination against Whooping Cough. 2016. Available online: https:/www.santepubliquefrance.fr/determinants-de-sante/vaccination/documents/ depliant-flyer/la-vaccination-contre-la-coqueluche-rpvp-mars-2016 (accessed on 14 February 2019). (In French)

34. Hellenbrand, W.; Beier, D.; Jensen, E.; Littmann, M.; Meyer, C.; Oppermann, H.; von König, C.H.; Reiter, S. The epidemiology of pertussis in Germany: Past and present. BMC Infect. Dis. 2009, 9, 22-33. [CrossRef] [PubMed]

35. Robert Koch Institute. Epidemiology Bulletin; Robert Koch Institute: Berlin, Germany, 2000. (In German)

36. Robert Koch Institute. Epidemiology Bulletin; Robert Koch Institute: Berlin, Germany, 2001. (In German)

37. Robert Koch Institute. Epidemiology Bulletin; Robert Koch Institute: Berlin, Germany, 2006. (In German)

38. Cocoran, B. National Immunisation Study Day. The National Immunisation Schedule Update and Current Issues. Dublin. 12 September 2014. Available online: https://www.hse.ie/eng/health/immunisation/hcpinfo/ conference/conference120914.html (accessed on 19 February 2019).

39. Health Service Executive National Immunisation Office. Immunisation Schedule. Available online: https: //www.hse.ie/eng/health/immunisation/pubinfo/pcischedule/immschedule/ (accessed on 10 February 2019).

40. Gonfiantini, M.V.; Carloni, E.; Gesualdo, F.; Pandolfi, E.; Agricola, E.; Rizzuto, E.; Iannazzo, S.; Degli Atti, M.C.; Villani, A.; Tozzi, A.E. Epidemiology of pertussis in Italy: Disease trends over the last century. Euro Surveill. 2014, 19, 20921. [CrossRef] [PubMed]

41. The Italian Vaccine Coverage Survey Working Group. Childhood vaccination coverage in Italy: Results of a seven-region survey. Bull. World Health Organ. 1994, 72, 885-895.

42. Bonanni, P.; Ferro, A.; Guerra, R.; Iannazzo, S.; Odone, A.; Pompa, M.G.; Rizzuto, E.; Signorelli, C. Vaccine coverage in Italy and assessment of the 2012-2014 National Immunization Prevention Plan. Epidemiol. Prev. 2015, 39 (Suppl. 1), 145-158.

43. The National Institute for Public Health and the Environment (RIVM). Adverse Events in the Netherlands Vaccination Programme. Available online: https://www.rivm.nl/bibliotheek/rapporten/205051004.pdf (accessed on 10 February 2019).

44. Lavine, J.; Bjørnstada, O.N.; de Blasio, B.F.; Storsaeter, J. Short-lived immunity against pertussis, age-specific routes of transmission, and the utility of a teenage booster vaccine. Vaccine 2011, 30, 544-551. [CrossRef]

45. Bednarek, A.; Bodajko-Grochowska, A.; Hasiec, B.; Klepacz, R.; Szczekala, K.; Zarzycka, D.; Emeryk, A. In search of factors negatively affecting vaccine immunity to pertussis in preschool children before the administration of the first booster. Int. J. Environ. Res. Public Health 2018, 15, 1432. [CrossRef]

46. National Institute of Public Health-National Institute of Hygiene (NIPH-NIH). Immunization Schedule. Available online: http://szczepienia.pzh.gov.pl/en/immunization-schedule/ (accessed on 14 February 2019).

47. Latasa, P.; García-Comas, L.; Gil de Miguel, A.; Barranco, M.D.; Rodero, I.; Sanz, J.C.; Ordobás, M.; Arce, A.; Garrido-Estepa, M. Effectiveness of acellular pertussis vaccine and evolution of pertussis incidence in the community of Madrid from 1998 to 2015. Vaccine 2018, 36, 1643-1649. [CrossRef]

48. Working Group of Whooping Cough, Ministry of Health, Social Service and Equality. Review of the Program of Vaccination against Whooping Cough in Spain; Ministry of Health, Social Service and Equality: Madrid, Spain, 2012. (In Spanish)

49. Hallander, H.; Gustafsson, L. Efficiacy and effectiveness of acellular pertussis vaccines: A 20-year Swedish experience. Expert Rev. Vaccines 2009, 8, 1303-1307. [CrossRef]

50. Aronsson, B.; Källberg, H.; Byström, E.; Drakes-Jämtberg, K. Pertussis surveillance in Sweden: Progress report October1997-December 2018 with an executive summary. The Public Health Agency of Sweden. 2017. Available online: https://www.folkhalsomyndigheten.se (accessed on 14 February 2019). 
51. Thierry-Carstensen, B.; Dalby, T.; Stevner, M.A.; Robbins, J.B.; Schneerson, R.; Trollfors, B. Experience with monocomponent acellular pertussis combination vaccines for infants, children, adolescents and adults-A review of safety, immunogenicity, efficacy and effectiveness studies and 15 years of field experience. Vaccine 2013, 31, 5178-5191. [CrossRef]

52. Comparative Efficacy/Effectiveness of Schedules in Infant Immunization Against Pertussis, Diphtheria and Tetanus: Systematic Review and Meta-Analysis. Available online: https://www.who.int/immunization/sage/ meetings/2015/april/6_Report_wP_140813.pdf?ua=1 (accessed on 27 May 2019).

53. Olin, P.; Hallander, H.O.; Gustafsson, L.; Barreto, L.; Podda, A. Measuring protection; a case study of pertussis vaccines-Swedish Trial II: Secondary non-randomized comparisons between two schedules of infant vaccination. Dev. Biol. Stand. 1998, 95, 211-220. [PubMed]

54. Miller, E.; Ashworth, M.A.E.; Redhead, K.; Thornton, C.; Waight, P.A.; Coleman, T. Effect of schedule on reactogenicity and antibody persistence of acellular and whole-cell pertussis vaccines: Value of laboratory tests as predictors of clinical performance. Vaccine 1997, 15, 51-60. [CrossRef]

55. DiCicco-Bloom, B.; Crabtree, B.F. The qualitative research interview. Med. Educ. 2006, 40, 314-321. [CrossRef] [PubMed]

56. Given, L.M. The SAGE Encyclopedia of Qualitative Research Methods; SAGE: Los Angeles, CA, USA, 2008; pp. 810-811.

57. Boyce, C.; Neale, P. Conducting in-Depth Interview: A Guide for Designing and Conducting in-Depth Interviews for Evaluation Input; Pathfinder International: Watertown, NY, USA, 2006; pp. 11-12.

58. Holton, J.A. The coding process and its challenges. Grounded Theory Rev. 2010, 9, 21-40.

59. Campbell, J.L.; Quincy, C.; Osserman, J.; Pedersen, O.K. Coding in-depth semistructured interviews: Problems of unitization and intercoder reliability and agreement. Sociol. Methods Res. 2013, 42, 294-320. [CrossRef]

60. Krippendorff, K. Content Analysis: An Introduction to Its Methodology, 2nd ed.; SAGE: London, UK, 2004; pp. 221-251.

61. Landis, J.R.; Kock, G.G. The measurement of observer agreement for categorical data. Biometrics 1977, 33, 159-174. [CrossRef]

62. World Health Organization. Immunization, Vaccines and Biologicals: Pertussis. Available online: https: //www.who.int/immunization/diseases/pertussis/en/ (accessed on 27 May 2019).

63. Silva, M.L.; Perrier, L.; Paget, J.W.; Mosnier, A.; Buthion, V.; Cohen, J.M.; Späth, H.M. Influenza vaccination policy-making process in France and the Netherlands: Framework and determinants. Health Policy 2016, 120, 293-305. [CrossRef]

64. Public Health England. Laboratory Confirmed Cases of Pertussis (England): January to March 2019. Available online: https://assets.publishing.service.gov.uk/government/uploads/system/uploads/attachment_ data/file/813292/hpr2219_prtsss.pdf (accessed on 7 July 2019).

65. High Authority of Health (HAS). The Vaccination against Whooping Cough for Pregnant Women in the Context of Epidemic in Mayotte. 2018. Available online: https://www.has-sante.fr/jcms/c_2848157/ $\mathrm{fr} /$ vaccination-contre-la-coqueluche-chez-la-femme-enceinte-dans-un-contexte-epidemique-a-mayotte (accessed on 15 August 2019). (In French)

66. High Authority of Health (HAS). The Vaccination against Whooping Cough for Pregnant Women. 2019. Available online: https://www.has-sante.fr/upload/docs/application/pdf/2019-07/recommandation vaccinale_contre_la_coqueluche_chez_la_femme_enceinte_feuille_de_route.pdf (accessed on 15 August 2019). (In French)

67. Kvale, S. Ten standard objections to qualitative research interviews. J. Phenomenol. Psychol. 1994, 25, $147-173$. [CrossRef]

68. Seale, C.; Silverman, D. Ensuring rigour in qualitative research. Eur. J. Public Health 1997, 7, 379-384. [CrossRef]

69. Qualitative Interview: When Enough Is Enough. Available online: http://www.raptureconsulting.com/ uploads/2/4/3/8/24380515/how_many_qualitative_interviews.pdf (accessed on 20 February 2019).

70. Geyer, R.; Rihani, S. Complexity and Public Policy: A New Approach to 21st Century Politics, Policy, and Society, 1st ed.; Routledge: New York, NY, USA, 2010.

(C) 2020 by the authors. Licensee MDPI, Basel, Switzerland. This article is an open access article distributed under the terms and conditions of the Creative Commons Attribution (CC BY) license (http://creativecommons.org/licenses/by/4.0/). 